OPEN ACCESS

Edited by:

Yukihiro Ohno,

Osaka University of Pharmaceutical

Sciences, Japan

Reviewed by:

Kenji Hashimoto,

Chiba University, Japan Karolina Pytka

Jagiellonian University, Poland

${ }^{*}$ Correspondence:

Pascal Bonaventure

pbonave1@its.jnj.com

Specialty section:

This article was submitted to

Neuropharmacology,

a section of the journal

Frontiers in Pharmacology

Received: 30 March 2017

Accepted: 24 May 2017

Published: 09 June 2017

Citation:

Bonaventure $P$, Dugovic $C$ Shireman $B$, Preville $C$, Yun $S$,

Lord B, Nepomuceno $D$,

Wennerholm $M$, Lovenberg $T$,

Carruthers N, Fitz SD, Shekhar A and Johnson PL (2017) Evaluation

of JNJ-54717793 a Novel Brain Penetrant Selective Orexin 1 Receptor

Antagonist in Two Rat Models

of Panic Attack Provocation.

Front. Pharmacol. 8:357.

doi: 10.3389/fphar.2017.00357

\section{Evaluation of JNJ-54717793 a Novel Brain Penetrant Selective Orexin 1 Receptor Antagonist in Two Rat Models of Panic Attack Provocation}

Pascal Bonaventure ${ }^{\text {* }}$, Christine Dugovic1 ${ }^{1}$ Brock Shireman1, Cathy Preville1, Sujin Yun', Brian Lord ${ }^{1}$, Diane Nepomuceno ${ }^{1}$, Michelle Wennerholm ${ }^{1}$, Timothy Lovenberg ${ }^{1}$, Nicolas Carruthers ${ }^{1}$, Stephanie D. Fitz ${ }^{2}$, Anantha Shekhar ${ }^{2,3}$ and Philip L. Johnson ${ }^{4,3}$

\footnotetext{
' Janssen Research \& Development, LLC, San Diego, CA, United States, ${ }^{2}$ Department of Psychiatry, Indiana University School of Medicine, Indianapolis, IN, United States, ${ }^{3}$ Stark Neurosciences Research Institute, Indiana University School of Medicine, Indianapolis, IN, United States, ${ }^{4}$ Department of Anatomy and Cell Biology, Indiana University School of Medicine, Indianapolis, IN, United States
}

Orexin neurons originating in the perifornical and lateral hypothalamic area are highly reactive to anxiogenic stimuli and have strong projections to anxiety and panic-associated circuitry. Recent studies support a role for the orexin system and in particular the orexin 1 receptor (OX1R) in coordinating an integrative stress response. However, no selective OX1R antagonist has been systematically tested in two preclinical models of using panicogenic stimuli that induce panic attack in the majority of people with panic disorder, namely an acute hypercapnia-panic provocation model and a model involving chronic inhibition of GABA synthesis in the perifornical hypothalamic area followed by intravenous sodium lactate infusion. Here we report on a novel brain penetrant, selective and high affinity OX1R antagonist JNJ-54717793 (1S,2R,4R)-7-([(3-fluoro-2-pyrimidin-2-ylphenyl)carbonyl]- $N$ [5-(trifluoromethyl)pyrazin-2-yl]-7-azabicyclo[2.2.1] heptan-2-amine). JNJ-54717793 is a high affinity/potent OX1R antagonist and has an excellent selectivity profile including 50 fold versus the OX2R. Ex vivo receptor binding studies demonstrated that after oral administration JNJ-54717793 crossed the blood brain barrier and occupied OX1Rs in the rat brain. While $\mathrm{JNJ}-54717793$ had minimal effect on spontaneous sleep in rats and in wild-type mice, its administration in OX2R knockout mice, selectively promoted rapid eye movement sleep, demonstrating target engagement and specific OX1R blockade. $\mathrm{JNJ}-54717793$ attenuated $\mathrm{CO}_{2}$ and sodium lactate induced panic-like behaviors and cardiovascular responses without altering baseline locomotor or autonomic activity. These data confirm that selective OX1R antagonism may represent a novel approach of treating anxiety disorders, with no apparent sedative effects.

Keywords: orexin, hypocretin, panic, anxiety, hypercapnia 


\section{INTRODUCTION}

Orexin neurons are located in the perifornical and lateral hypothalamus of rodents (Peyron et al., 1998), and humans (Thannickal et al., 2007). The role of orexins (OX-A and $\mathrm{OX}-\mathrm{B}$ ) and orexin receptors (OX1R and OX2R) in complex emotional behavior including innate anxiety and panic and fear associated learning is emerging (Johnson et al., 2010; Boss and Roch, 2015; Flores et al., 2015). For instance, optogenetically stimulating orexin neurons in rats increases anxiety-like states in anxiety-related neural circuits (Heydendael et al., 2013) as well as stress hormone release and tachycardia (Bonnavion et al., 2015). In addition, artificially increasing orexin-A levels in the cerebrospinal fluid of rodents increases anxiety associated behaviors (Suzuki et al., 2005), which is consistent with elevated orexin levels being associated with increases in anxiety symptoms in neuropsychiatric patients (Johnson et al., 2010). Severe anxiety such as panic attacks are also more prevalent during the wake phase (de Beurs et al., 1994) when orexin levels are at their highest levels in humans (Mignot et al., 2002) and in rats (Desarnaud et al., 2004).

Excitation of the perifornical hypothalamic area, which contains particularly high concentration of orexin neurons, produces robust flight and escape behaviors, and cardioexcitation in rodents (Shekhar and DiMicco, 1987; Anderson and DiMicco, 1990; Shekhar et al., 1990; Soltis and DiMicco, 1992; Samuels et al., 2002), and induces core symptoms of panic attacks in humans [e.g., fear of dying, cardiorespiratory symptoms, and thermal sensations (Rasche et al., 2006; Wilent et al., 2010, 2011)]. In orexin knockout mice, cardiovascular responses are diminished following perifornical hypothalamic area stimulation (Kuwaki et al., 2008). Panic disorder is characterized by recurrent spontaneous panic attacks, which can be reliably induced with interoceptive stimuli such as intravenous $0.5 \mathrm{M}$ sodium lactate and $5 \mathrm{~min}$ of $5-7 \%$ hypercapnic gas exposure, which do not induce panic attacks in healthy controls (Pitts and McClure, 1967; Woods et al., 1988; Gorman et al., 1994). Exposing healthy humans to higher concentrations of hypercapnic gas (i.e., $20 \% \mathrm{CO}_{2}$ inhalation) will also induce core features of panic attacks (Forsyth et al., 2000). Collectively, these two panic paradigms can be modeled in rats: (1) chronic disinhibition of the perifornical hypothalamic area orexin region also produces rats that are vulnerable to displaying panic-like responses to interoceptive stimuli, such as sodium lactate (see review, Johnson and Shekhar, 2012); and (2) exposing naïve rats to $20 \%$ hypercapnic gas exposure also induces panic-associated responses. Both panic models, using stimuli that signal a threatening internal body state change, activate OX neurons in the perifornical hypothalamic area (Williams et al., 2007; Johnson et al., 2010, 2012c,d) and increase panic associated behaviors (e.g., flight like locomotion and anxiety in a social interaction (SI) test and defensive burying test) and panic associated dyspnea (Hickman et al., 2016) and cardioexcitation (Johnson et al., 2010, 2012c,d, 2015). In these panic models, silencing prepro orexin (sodium lactate only) or selective OX1R antagonists attenuate panic-like responses to $\mathrm{CO}_{2}$ and sodium lactate (Johnson et al., 2010, 2012c, 2015). Additionally, in rats a selective OX1R antagonist blocks cellular responses in panic and anxiety brain circuits (e.g., amygdala and dorsal periaqueductal gray and sympathetic nuclei) post-administration of a panicogenic drug (Johnson et al., 2012c), and in humans recent imaging data indicate that a selective OX1R antagonist produced a region-dependent inhibition of yohimbine-induced activation in fronto-hippocampal regions as well as in several key components of the extended amygdala (Gozzi et al., 2013). The OX1R inhibition in the amygdala is consistent with preclinical studies demonstrating that the OX system is implicated in amygdala regulation of fear-associated learning (Johnson et al., 2012a; Sears et al., 2013; Flores et al., 2014). Overall, there is compelling evidence that overactivation of the OX1R pathway is associated with hyper-excited or hyperactive states; thus conceptually, a selective OX1R antagonist might normalize overexcited networks without inducing sedation (Bonaventure et al., 2015b). Based on these preclinical data, we developed a selective OX1R antagonist with suitable druglike properties. A separate paper describes the new OX1R antagonist JNJ-54717793 (Figure 1) synthesis, structure activity relationship, pharmacokinetics in preclinical species (Shireman et al., submitted).

Here, we report a comprehensive pharmacological characterization of JNJ-54717793 and its evaluation in two well-established models of panic provocation. In vitro affinity and potency for the human and rat OX1R were determined by radioligand binding and in vitro functional assays. In vivo target engagement was measured after oral dosing of JNJ-54717793 in rat brain using ex vivo receptor occupancy. We have recently shown that while selective OX1R antagonism did not affect sleepwake states, additional pharmacological blockade of OX1R to OX2R inhibition elicited a disinhibition of rapid eye movement (REM) in rats and mice (Dugovic et al., 2014). Therefore, the effect of the selective OX1R antagonist on sleep was tested in $\mathrm{OX} 2 \mathrm{R}$ knockout $(\mathrm{KO})$ mice to demonstrate in vivo functional target engagement.

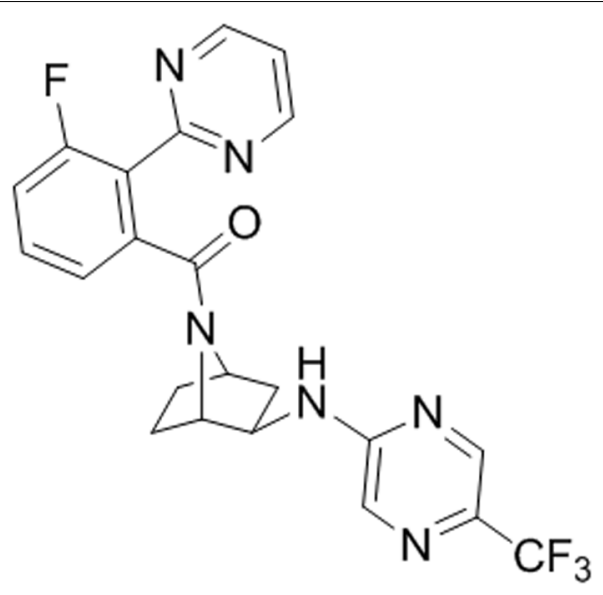

FIGURE 1 | Chemical structure of JNJ-54717793

(1S,2R,4R)-7-([(3-fluoro-2-pyrimidin-2-ylphenyl)carbonyl]- $N$-[5-

(trifluoromethyl)pyrazin-2-yl]-7-azabicyclo[2.2.1] heptan-2-amine). 


\section{MATERIALS AND METHODS}

\section{Chemicals}

Almorexant, EMPA, GSK-1059865, SB-674042, and JNJ54717793 were synthetized at Janssen Research \& Development, LLC. Peptides were obtained from Bachem (Torrance, CA, United States).

\section{Animals}

All animal procedures performed in this study were in accordance with the Guide for Care and Use of Laboratory Animals adopted by the US National Institutes of Health $\mathrm{NIH}$ Publication no. 80-23 revised 1996) and the guidelines of the Institutional Animal Care and Use Committee. Animals were housed under controlled conditions with a 12/12 h light/dark schedule and temperature of $22 \pm 2^{\circ} \mathrm{C}$. Food and water were provided ad libitum. Experiments were performed after animals had acclimated for at least 1 week unless stated otherwise.

\section{In Vitro Radioligand Binding Assays}

Human or rat OX1R binding was measured in competitive radioligand binding assays using $\left[{ }^{3} \mathrm{H}\right] \mathrm{SB}-674042$ (1-(5-(2-fluoro -phenyl)-2-methyl-thiazol-4-yl)-1-((S)-2-(5-phenyl-(1,3,4)oxadiazol-2-ylmethyl)-pyrrolidin-l-yl)-methanone) as a tracer (4 $\mathrm{nM}$, specific activity $35 \mathrm{Ci} / \mathrm{mmol}$ ) as previously described (Langmead et al., 2004). Cell membranes were prepared from clonal CHO K1 cells transfected with the human OX1R or clonal HEK-293 cells transfected with the rat OX1R. Dilutions of test compounds were made in Dulbecco's PBS from $10 \mathrm{mM}$ stocks dissolved in dimethyl sulfoxide. After a $60 \mathrm{~min}$ incubation at room temperature, binding reactions were filtered. The membranes were counted in a scintillation counter. Nonspecific binding was determined in the presence of $10 \mu \mathrm{M}$ almorexant. Affinities of compounds for the human OX2R were measured by competitive radioligand binding using tritiated $N$-ethyl-2-[(6-methoxy-pyridin-3-yl)-(toluene-2-sulfonyl)-

amino]- $N$-pyridin-3-ylmethyl-acetamide (EMPA) (2 nM, specific activity $27 \mathrm{Ci} / \mathrm{mmol}$ ) (Malherbe et al., 2009). Cell membranes were prepared from a stable pool of HEK-293 cells transfected with the human OX2R. Non-specific binding was determined with $10 \mu \mathrm{M}$ almorexant.

The $\mathrm{K}_{i}$ of the test compounds was calculated based on nonlinear regression (one site competition) using Graphpad Prism.

The selectivity of JNJ-54717793 was evaluated in a large variety of ion-channels, transporters and receptor-binding assays. These assays were performed by Eurofins (Celles L'Evescault, France).

\section{In Vitro Functional Assays (Calcium Mobilization Assays)}

Stably transfected CHO-K1 cells for the human OX1R or HEK293 cells for the rat OX1R were used for the in vitro functional assays. The human OX2R functional assay used PFSK-1 cells which are a human neuroectodermal cell line that innately expresses the OX2R. Since the intracellular calcium response is transient and not consistent with equilibrium assumptions, the assays were performed by giving a standard, $\mathrm{EC}_{80}$ dose of the $\mathrm{OX}$ agonist and calculating a $\mathrm{pK}_{B}$ from inhibition of the agonist response by a dose range of the antagonists. The cells were plated in black 96 well tissue culture plates with clear bottoms at 50,000 cells/well and grown overnight at $37^{\circ} \mathrm{C}$ in $5 \%$ carbon dioxide $\left(\mathrm{CO}_{2}\right)$. Dilutions of the antagonist were prepared in Hanks Balanced Salt Solution (HBSS) from 10 mM DMSO stocks, while dilutions of OX peptides (OX-A for OX1R assays, OX-B for OX2R assays) were prepared in HBSS $+0.1 \%$ bovine serum albumin. On the day of the assay, a $2 \mathrm{X}$ dye-loading solution (BD Calcium Assay Kit) was added to the cells and incubated for $45 \mathrm{~min}$ at $37^{\circ} \mathrm{C}$ in $5 \% \mathrm{CO}_{2}$. Dilutions of the test compounds were added and the cells were incubated at room temperature for $15 \mathrm{~min}$. The cell plate was then transferred to the Molecular Devices Fluorometric Imaging Plate Reader (FLIPR) Tetra instrument, which adds the OX agonist and monitors changes in fluorescence which reflect intracellular calcium levels.

Results were calculated using GraphPad Prism (San Diego, CA, United States) software. Raw data from the FLIPR Tetra was exported as the difference between maximum and minimum fluorescence observed for each well. A non-linear regression was used to determine the agonist $\mathrm{EC}_{50}$ and antagonist $\mathrm{IC}_{50}$ for each plate, then the antagonist $\mathrm{K}_{B}$ was calculated according to Cheng and Prusoff (Cheng and Prusoff, 1973).

\section{Ex Vivo Receptor Occupancy Assay}

Experiments were performed as previously described (Dugovic et al., 2009) in male Sprague-Dawley rats (300-400 g, Charles River Laboratories, San Diego, CA, United States). The animals were euthanized using carbon dioxide and decapitated at different time points after drug administration $(n=3$ per time point or dose regimen). Brains were rapidly frozen on powdered dry ice and stored at $-80^{\circ} \mathrm{C}$ before sectioning. Plasma samples were also collected for bioanalysis (LC-MS/MS). Twenty micron thick tissue sections at the level of the tenia tecta were prepared for autoradiography. OX1R radioligand binding autoradiography was determined at room temperature with $\left.5 \mathrm{nM} \mathrm{[}{ }^{3} \mathrm{H}\right] \mathrm{SB}-674042$. Sections were incubated for $10 \mathrm{~min}$ to minimize dissociation. Non-specific binding was determined in the presence of $10 \mu \mathrm{M}$ SB-674042. Ex vivo receptor labeling was expressed as the percentage of receptor labeling in corresponding brain areas (i.e., tenia tecta) of vehicle-treated animals. The percentage of receptor occupancy was plotted against time or dosage using GraphPad Prism (GraphPad Software, San Diego, CA, United States). Percentage of receptor occupancy was also plotted against drug plasma or brain concentration. Pharmacokinetic parameters were analyzed using a non-compartmental model using the software package WinNonlin Version 4.0.1 (Pharsight, Palo Alto, CA, United States).

\section{Sleep Recording and Analysis in Rats and Mice}

Sleep experiments were conducted in male Sprague-Dawley rats (350-450 g, Harlan Laboratories, Livermore, CA, United States) and in male C57Bl6 OX2R knockout (KO) and corresponding wild-type mice (30-35 g, Charles River Laboratories, San Diego, CA, United States) as described previously (Dugovic et al., 2009). Animals were chronically implanted with telemetric devices (Data Sciences International, St. Paul, MN, United States) for the recording of electroencephalogram (EEG) and electromyogram 
(EMG) signals. Polysomnographic waveforms were analyzed per 10-s epoch and classified as wake, non-rapid eye movement (NREM) or REM sleep by using the computer software program SleepSign (Kissei Comtec, Nagano, Japan). For each experiment, EEG and EMG signals were recorded for up to $6 \mathrm{~h}$ after administration of the tested compounds. Analysis of sleep parameters included latency to NREM sleep (defined as the time interval to the first six consecutive NREM epochs) and REM sleep (the first two consecutive REM epochs post-treatment), and the duration of NREM and REM.

Results were averaged and expressed as mean \pm SEM in defined time intervals. To determine whether differences were significant at a given interval, either paired Student's $t$-test or two-way analysis of variance (ANOVA) (interaction time $\times$ treatment), repeated measures followed by Bonferroni post hoc test was performed.

\section{Normoxic, $20 \% \mathrm{CO}_{2}$ Panic Provocation Model}

Experiments were performed in male Sprague-Dawley rats (300-350 g, Harlan Laboratory, Indianapolis, IN, United States). Using $\mathrm{CO}_{2}\left(\mathrm{ProCO}_{2}\right)$ and $\mathrm{O}_{2}\left(\mathrm{ProO}_{2}\right)$ sensors in our enclosed flow cages (12 inch width $\times 12$ inch height $\times 24$ inch length), we have previously verified that $\mathrm{O}_{2}$ and $\mathrm{CO}_{2}$ concentrations remain normal with atmospheric air infusion, and that only the $\mathrm{CO}_{2}$ concentrations rapidly increase from $<1$ to $20 \%$ at the 5 min time point for $\mathrm{CO}_{2}$ challenge (Johnson et al., 2005). In a counter-balanced design (i.e., all rats received each drug treatment with at least $48 \mathrm{~h}$ between treatments), rats were systemically treated with a control vehicle or a selective OX1R antagonist, and then placed into the chamber where atmospheric air was being infused. All rats had infusions of the following: (1) $5 \mathrm{~min}$ infusion of atmospheric gas $\left(<1 \% \mathrm{CO}_{2}, 21 \% \mathrm{O}_{2}\right.$, $79 \% \mathrm{~N}_{2}$ : Praxair, Inc.) for baseline measurements ( $\sim 45-60 \mathrm{~min}$ post-treatment), then (2) either the control gas or experimental normoxic, hypercarbic gas $\left(20 \% \mathrm{CO}_{2}, 21 \% \mathrm{O}_{2}, 59 \% \mathrm{~N}_{2}\right.$ : Praxair $)$ for $5 \mathrm{~min}$ (note: for control rats the atmospheric gas was turned off and back on again at the beginning and end of this infusion to be identical to the manipulations for the hypercarbic gas challenge), and finally (3) 5 min infusion of atmospheric gas. Following exposure to hypercarbic and atmospheric air gasses, rats were immediately placed in the open-field box for a $5 \mathrm{~min}$ period then assessed in SI test for $5 \mathrm{~min}$. The data reported are changes in activity, expressed in $1 \mathrm{~min}$ bins, relative to the average of the baseline measurement ( $t-5$ to $t-1$ minute) from each rat.

\section{Sodium Lactate Panic Provocation Model}

Experiments were performed in male Sprague-Dawley rats (300-350 g, Harlan Laboratory, Indianapolis, IN, United States). Prior to and during surgeries, rats were anesthetized with a nose cone connected to an isoflurane system (MGX Research Machine; Vetamic, Rossville, IN, United States). Radiotelemetry probes [Cat. no. HD-S11, Data Sciences International, St. Paul, MN, United States] were surgically implanted into the peritoneal cavity and sutured to the muscle wall in order to assess general motor activity. A pressure transducer was implanted into the femoral artery to assess cardiovascular responses [i.e., mean arterial blood pressure (MAP) and heart rate (HR)]. Rats were also fitted with femoral venous catheters for $0.5 \mathrm{M}$ i.v. sodium lactate (NaLac) infusions, as previously described (Shekhar et al., 1996). After 3-5 days of recovery, rats were anesthetized and 26 gauge T-shaped cannulae (Cat. no. 3260PG, Plastics One, Inc., Roanoake, VA, United States) were directed at cardio-excitatory Perifornical hypothalamic area regions [(Shekhar and Keim, 1997) bregma: $1.2 \mathrm{~mm}$ posterior, $+2.1 \mathrm{~mm}$ lateral, $+9.1 \mathrm{~mm}$ ventral and adjusted for approaching at a $10^{\circ}$ angle toward the midline with the stereotaxic incisor bar elevated $5 \mathrm{~mm}$ above the interaural line] and cemented into place. The 22 gauge side arm was then attached, via PE-60 tubing, to an osmotic minipump (prefilled with 1-allyglycine solution chronically infused at $3.5 \mathrm{nmol} / 0.5 \mu \mathrm{l}$ per hour) and sutured into place subcutaneously at the nape of the neck (DURECT Corporation, Model no. 2002). Previous studies have determined that the dose of 1allyglycine utilized here reduces local GABA concentrations by approximately $60 \%$ following unilateral infusions (Shekhar and DiMicco, 1987; Abshire et al., 1988; Shekhar et al., 1996, 2006; Shekhar and Keim, 1997).

Five days following 1-allyglycine infusion onset, in a counterbalanced design and with $48 \mathrm{~h}$ between crossover, rats were orally dosed with either JNJ-54717793 at 3, 10, or $30 \mathrm{mg} / \mathrm{kg}$, or vehicle as a control group $60 \mathrm{~min}$ prior to the $15 \mathrm{~min} 0.5 \mathrm{M}$ sodium lactate challenge. DSI DATAQUEST software was used to monitor and record mean arterial pressure, $\mathrm{HR}$, and motor activity which were recorded continuously in freely moving conscious rats and are expressed as a $20 \mathrm{~min}$ time course. The data reported are changes in mean arterial blood pressure, HR, and activity from the average of the baseline ( $t-5$ to $t-1)$ from each rat.

Baseline SI testing was done 7-8 days following radiotelemetry surgery recovery, and repeated again 2-3 days later during drug treatment crossover. On experimental drug testing days, the SI test was performed $5 \mathrm{~min}$ after the offset of the sodium lactate challenge with different partners each time. The SI box dimension were $0.9 \mathrm{~m}$ long $\times 0.9 \mathrm{~m}$ wide $\times 0.3 \mathrm{~m}$ height. The SI test is a validated test of experimental anxiety-like behavior in rats that is sensitive to FDA approved treatments for anxiety disorder symptom management that includes benzodiazepines and selective serotonin reuptake inhibitors (SSRIs) (Sanders and Shekhar, 1995; Shekhar and Katner, 1995). All behavioral tests were digitally videorecorded with a camera above the box. The "experimental" rat and an unfamiliar "partner" rat were both allowed to individually habituate to the box for a $5 \mathrm{~min}$ period $24 \mathrm{~h}$ prior to each SI test. During the SI test, the two rats were placed together in the center of the box, and the total duration (sec) of non-aggressive physical contact (grooming, sniffing, crawling over and under, etc.) initiated by the "experimental" rat is quantified over a 5 min duration. A baseline SI test was performed at least $72 \mathrm{~h}$ after i.v. catheterization, but prior to osmotic minipump implantation. Another SI test was performed 5 days following minipump infusions and immediately following saline or sodium lactate infusions. Video recorded sessions were scored at a later time by Stephanie D Fitz, whom was blind to any drug treatment.

Following experiments, all rats were anesthetized and decapitated, their brains were removed, frozen, sectioned 
(30 $\mu \mathrm{m})$ and stained with Neutral Red for determination of injection cannulae placements.

Each dependent variable for assessment of behavior and radiotelemetry data was respectively analyzed using a one way ANOVA, or a one way ANOVA with repeated measures with drug treatment as the main factor and time as repeated measures. In the presence of significant main effects post hoc tests were conducted using a parametric Fisher's LSD test. Within subjects time effects were also assessed using a Dunnett's one way analysis with the minute prior to the i.v infusion used as the control. Statistical significance was accepted with $p<0.05$. All statistical analyses were carried out using SPSS 13.0 (SPSS, Inc., Chicago, IL, United States) and all graphs were generated using SigmaPlot 2001 (SPSS, Inc., Chicago, IL, United States) or Graphpad Prizm 7 Software, Inc. for Windows.

\section{RESULTS}

\section{JNJ-54717793 is a Selective High Affinity OX1R Antagonist}

The affinity of JNJ-54717793 for the human and rat OX1R was determined by competitive radioligand binding using $\left[{ }^{3} \mathrm{H}\right]$ SB674042. To determine the selectivity ratio versus the OX2R, the affinity of the compounds for the human OX2R was determined by competitive radioligand binding using $\left[{ }^{3} \mathrm{H}\right]-\mathrm{EMPA}$ as the radioligand.

JNJ-54717793 showed high affinity binding to the human and rat $\mathrm{OX} 1 \mathrm{R}$, with $\mathrm{pK}_{i}$ values of 7.83 and $7.84 \mathrm{nM}$, respectively (Table 1). The binding selectivity of JNJ-54717793 at the human OX1R compared to the human OX2R was substantial ( $\sim 50$ fold).

JNJ-54717793 was assayed by binding in a panel of 50 receptors, ion channels and transporters assays including adenosine $\left(A_{1}, A_{2 A}, A_{3}\right)$, adrenergic $\left(\alpha_{1}, \alpha_{2}, \alpha_{1}\right)$, angiotensin $\left(\mathrm{AT}_{1}\right)$, dopamine $\left(\mathrm{D}_{1}, \mathrm{D}_{2}\right)$, bradykinin $\left(\mathrm{B}_{2}\right)$, cholecystokinin $\left(\mathrm{CCK}_{A}\right)$, galanin $\left(\mathrm{GAL}_{2}\right)$, melatonin $\left.\mathrm{ML}_{1}\right)$, muscarinic $\left(\mathrm{M}_{1}, \mathrm{M}_{2}\right.$, $\left.\mathrm{M}_{3}\right)$, neurotensin $\left(\mathrm{NT}_{1}\right)$, neurokinin $\left(\mathrm{NK}_{2}, \mathrm{NK}_{3}\right)$, opiate $(\mu, \kappa, \delta)$, serotonin $\left(5-\mathrm{HT}_{1 A}, 5-\mathrm{HT}_{1 B}, 5-\mathrm{HT}_{2 A}, \quad 5-\mathrm{HT}_{3}\right.$, $\left.5-\mathrm{HT}_{5 A}, \quad 5-\mathrm{HT}_{6}, \quad 5-\mathrm{HT}_{7}\right)$, somatostatin, vasopressin $\left(\mathrm{V}_{1 a}\right)$, norepinephrine transporter, dopamine transporter and ion channels (sodium, calcium, potassium, and chloride). JNJ54717793 at concentrations up to $10 \mu \mathrm{M}$ had no significant affinity for any receptor/transporter/ion channel $(<50 \%$ inhibition at $10 \mu \mathrm{M}$ ) other than the OX1R.

The functional antagonism of JNJ-54717793 for the human or rat OX1R was determined by measuring changes in intracellular

TABLE 1 | In vitro binding affinities $\left(\mathrm{pK}_{i}\right)$ and in vitro functional potencies $\left(\mathrm{pK}_{b}\right)$ of JNJ-54717793 at the human and rat OX1R and OX2R.

\begin{tabular}{lcc}
\hline & Affinity $\left.\mathbf{(} \mathbf{p} \mathbf{K}_{\mathbf{i}}\right)$ & Potency $\left(\mathbf{p} \mathbf{K}_{\mathbf{b}}\right)$ \\
\hline hOX1R & $7.83 \pm 0.16(12)$ & $7.78 \pm 0.31(5)$ \\
rOX1R & $7.84 \pm 0.12(17)$ & $7.45 \pm 0.20(2)$ \\
hOX2R & $6.14 \pm 0.14(16)$ & $6.51 \pm 0.24(4)$
\end{tabular}

The values are expressed as average \pm SEM, and the number of triplicate experiments is indicated between parentheses. calcium in cell culture assays in response to an $\mathrm{EC}_{80}$ dose of OX-A. Functional antagonism data, summarized in Table 1, showed that the high affinity OX1R binding of JNJ-54717793 was reflected in potent functional activity. The $\mathrm{pK}_{B}$ values correlated well with the $\mathrm{pK}_{i}$ values for the human and rat OX1R. The binding selectivity of JNJ-54717793 at the OX1R compared to the OX2R was confirmed at the functional level (Table 1).

\section{JNJ-54717793 Crosses the Blood Brain Barrier and Occupies the OX1R in Rat Brain after Systemic Administration}

In vivo occupancy of the OX1R was assessed by ex vivo receptor binding autoradiography of $\left[{ }^{3} \mathrm{H}\right] \mathrm{SB}-674042$ in rat brain tissue sections at the level of the tenia tecta. Time-dependency and dose-dependency were assessed after oral dosing (Figure 2).
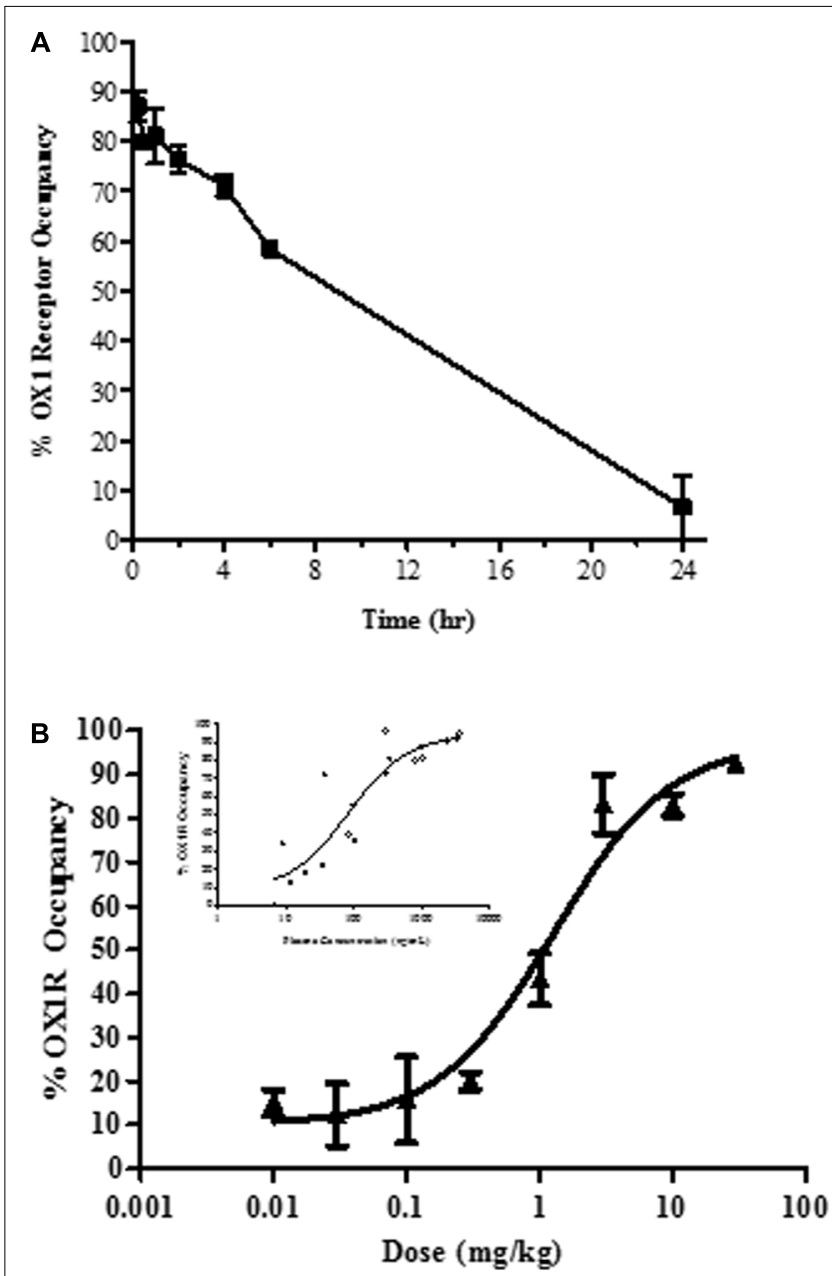

FIGURE 2 | EX vivo brain OX1R binding autoradiography by JNJ-54717793 measured in the tenia tecta (A) Duration of occupancy for JNJ-54717793 post-oral administration in rats $(30 \mathrm{mg} / \mathrm{kg}$ ). (B) Occupancy versus dose measured at $1 \mathrm{~h}$. Insert graph showed occupancy versus plasma exposure. Results are expressed as average percentage receptor occupancy versus vehicle treated rats $\pm \operatorname{SEM}(n=3)$. 
TABLE 2 | Effects of the OX1R antagonist JNJ-54717793 on sleep parameters in rats.

\begin{tabular}{|c|c|c|c|c|}
\hline & NREM latency & REM latency & NREM duration & REM duration \\
\hline Vehicle & $31.8 \pm 5.0$ & $66.2 \pm 2.1$ & $55.0 \pm 4.2$ & $6.3 \pm 1.2$ \\
\hline JNJ-54717793 & $26.6 \pm 3.2$ & $47.3 \pm 5.6^{*}$ & $59.5 \pm 2.7$ & $8.6 \pm 1.2$ \\
\hline
\end{tabular}

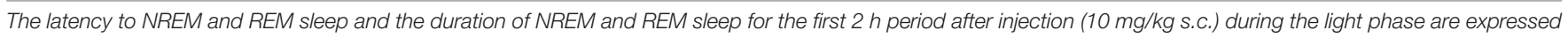
in minutes. Values represent mean \pm SEM $(n=6)$. ${ }^{*} p<0.05$ versus Vehicle as determined by paired Student's $t$-test.
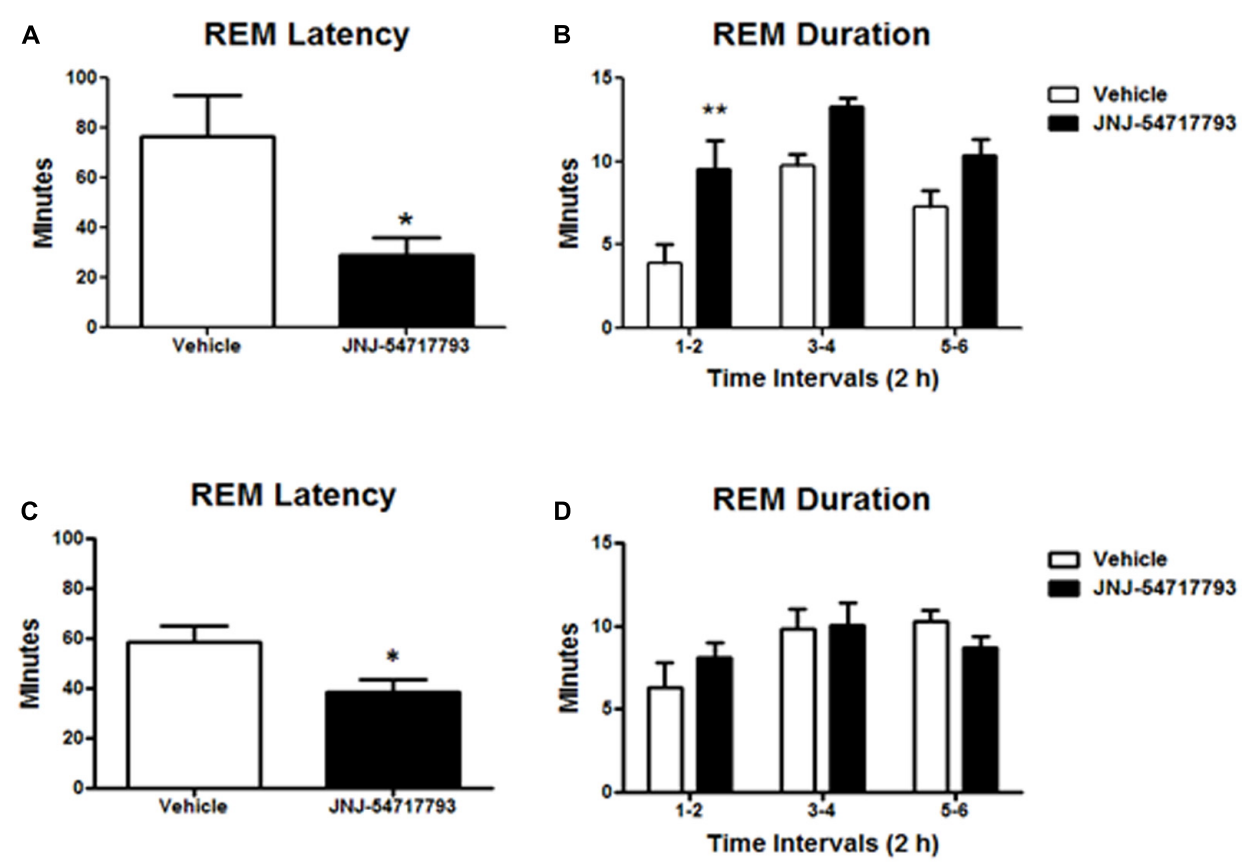

FIGURE 3 | Rapid eye movement (REM) sleep promoting effects of the OX1R antagonist JNJ-54717793 in OX2R KO mice. REM sleep latency and duration in OX2 $\mathrm{KO}$ mice $\mathbf{( A , B )}$ and wild-type $(\mathbf{C}, \mathbf{D})$ for the first $6 \mathrm{~h}$ period after oral dosing $(30 \mathrm{mg} / \mathrm{kg})$ during the light phase are expressed in minutes. Values represent the mean \pm SEM ( $n=7 \mathrm{KO}, n=5$ wild-type). ${ }^{*} p<0.05$ and ${ }^{* *} p<0.01$ versus Vehicle as determined by paired Student's $t$-test (latency) or two-way ANOVA followed by Bonferroni post hoc test (duration).

Oral administration of JNJ-54717793 inhibited $\left[{ }^{3} \mathrm{H}\right] \mathrm{SB}$ 674042 binding to the rat tenia tecta, indicating sufficient oral bioavailability and brain penetration. After acute oral administration of $30 \mathrm{mg} / \mathrm{kg}$, maximal OX1R occupancy was observed at $15 \mathrm{~min}(87 \pm 3 \%$, Figure $2 \mathrm{~A})$ corresponding to a plasma concentration of $3733 \pm 440 \mathrm{ng} / \mathrm{ml}$. The level of OX1R occupancy remained above $58 \%$ for the first $6 \mathrm{~h}$ and then drop to negligible level of occupancy.

For dose-dependency, ex vivo receptor occupancy was measured $60 \mathrm{~min}$ after drug treatment (close to the $\mathrm{T}_{\max }$, observed in a rat pharmacokinetic study, result not shown). The plateau for maximal OX1R occupancy ( $\sim 80$ to $90 \%)$ was reached at $3 \mathrm{mg} / \mathrm{kg}$ (Figure 2B) corresponding to a plasma concentration of $\sim 310.6 \pm 23.5 \mathrm{ng} / \mathrm{ml}$. The $\mathrm{ED}_{50}$ was measured at $1.3 \mathrm{mg} / \mathrm{kg}$ (corresponding to a plasma exposure of $84 \mathrm{ng} / \mathrm{ml}, 95 \%$ confidence interval 26 to $277 \mathrm{ng} / \mathrm{ml}$ ).

In vivo OX1R occupancy was also determined at various time points following subcutaneous dosing of $10 \mathrm{mg} / \mathrm{kg}$ of JNJ-54717793 (result not shown). Maximal OX1R occupancy $(83 \pm 7 \%)$ was observed at $30 \mathrm{~min}$. The plasma concentration for maximal receptor occupancy was determined to be
$2211 \pm 339 \mathrm{ng} / \mathrm{ml}$. At the $2 \mathrm{~h}$ time point, JNJ-54717793 still displayed 65\% OX1R occupancy.

\section{JNJ-54717793 Minimally Affects Spontaneous Sleep in Rats}

Rats were subcutaneously injected with the OX1R antagonist JNJ-54717793 $(10 \mathrm{mg} / \mathrm{kg})$ at $2 \mathrm{~h}$ into the light phase. There were no significant differences between JNJ-54717793 and vehicle conditions (paired Student's $t$-test) in most of the sleep parameters examined over the $2 \mathrm{~h}$ period following the treatment. Specifically, NREM sleep latency and duration were not altered. REM sleep latency was slightly but significantly reduced without producing a significant impact on REM sleep duration (Table 2).

\section{Transient OX1R Blockade by JNJ-54717793 Selectively Promotes REM Sleep in OX2R Knockout Mice}

Previous studies have demonstrated that OX1R antagonists produce a disinhibition of REM sleep in the presence of OX2R antagonism (Dugovic et al., 2014; Bonaventure et al., 2015b). In 

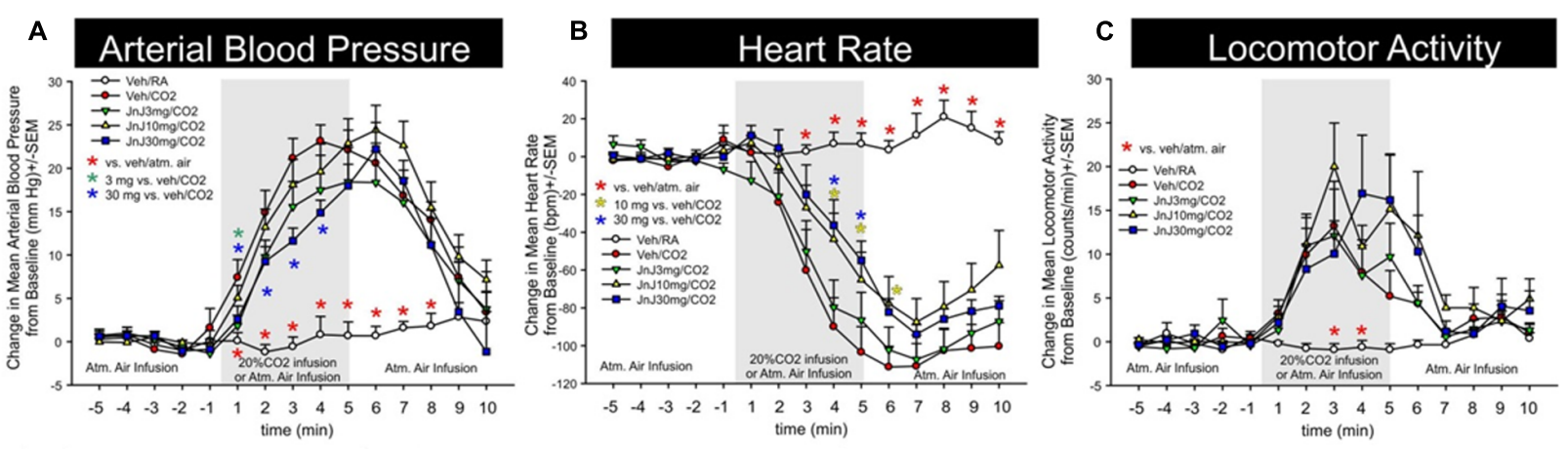

D Social Interaction

Open Field Test
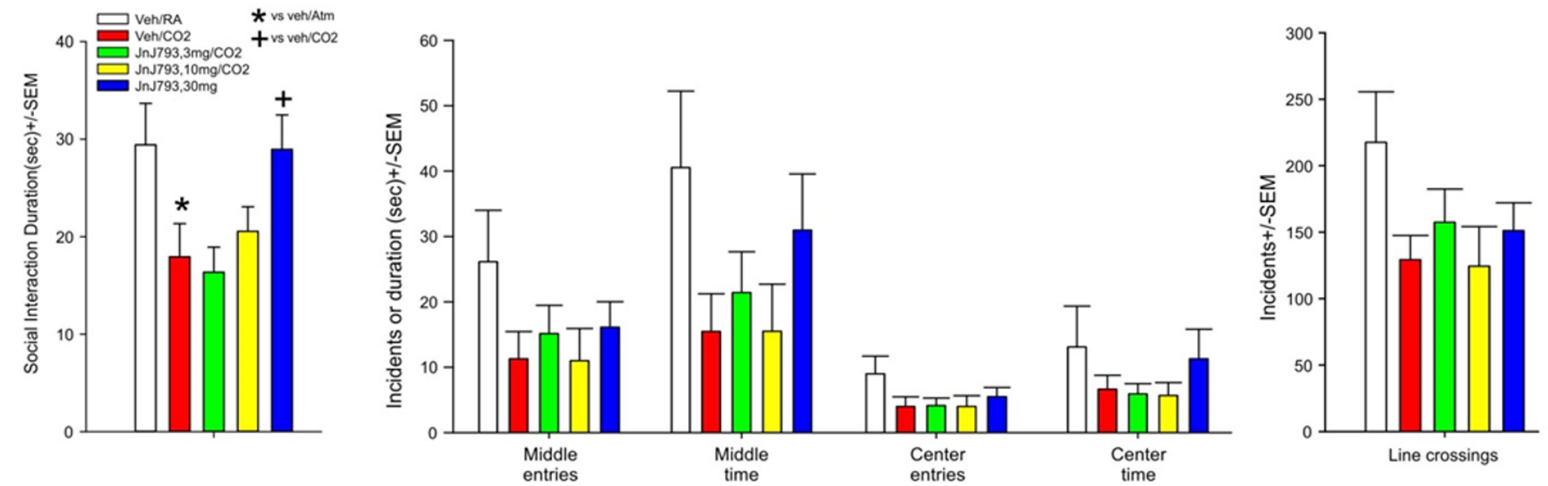

FIGURE 4 | Effect of JNJ-54717793 in a model of $\mathrm{CO}_{2}$ induced panic. Line graphs indicate the effects of oral gavage (p.o.) of vehicle, or 3,10 , or $30 \mathrm{mg} / \mathrm{kg}$ doses of JNJ-54717793 on $20 \% \mathrm{CO}_{2}$ induced changes (from 5 min baseline) in (A) mean arterial blood pressure (MAP, mm Hg), (B) heart rate (HR, beats/min, BPM), and (C) general locomotor activity (counts/min) in freely moving rats surgically implanted with radiotelemetry probes. There were no significant differences in baseline mean arterial blood pressure, $\mathrm{HR}$, or locomotor activity (t-5 to $\mathrm{t}-1$ ). Gray shaded area represents the $5 \mathrm{~min} \mathrm{CO}_{2}$ or atmospheric air challenge, where atmospheric air (RA) was also infused prior to and after for $5 \mathrm{~min}$ (also indicated at bottom of $x$-axis). ${ }^{*}$ Indicates between subjects differences using a Fisher's LSD post hoc test that was protected with a repeated measures ANOVA and an ANOVA at each time point, $\mathrm{p}<0.05$. Bar graphs indicate the effects of $\mathrm{JNJ}^{-54717793}$ on $20 \% \mathrm{CO}_{2}$ induced changes in (D) social interaction (SI) in the SI test, and (E) line crossings and middle and center time in the open field test. * and + respectively indicate between subjects differences between veh/RA and veh/CO $\mathrm{Cr}_{2}$ veh/ $\mathrm{CO}_{2}$ and $30 \mathrm{mg} / \mathrm{kg} \mathrm{JNJ}-54717793 / \mathrm{CO}_{2}$ using a Fisher's LSD post hoc test that was protected with an ANOVA, $p<0.05$.

the present study, the in vivo functional target engagement was investigated in a model of permanent inhibition of OX2R, and the effects of JNJ-5471773 on sleep-wake states were examined in mice lacking the OX2R relative to their corresponding wildtype mice. As compared to vehicle, oral dosing of JNJ-5471773 $(30 \mathrm{mg} / \mathrm{kg}$ ) at $2 \mathrm{~h}$ into the light phase to OX2R KO mice significantly reduced the latency for REM sleep and prolonged the time spent in REM sleep during the first $6 \mathrm{~h}$ post-treatment (Figures 3A,B). In wild-type mice, JNJ-5471773 slightly reduced REM sleep latency but did not alter REM sleep duration (Figures 3C,D). NREM sleep latency and duration were not affected in both genotypes (not shown).

\section{Effect of JNJ-54717793 in a Model of $\mathrm{CO}_{2}$ Induced Panic}

Activation of the OX1R is a critical component of $\mathrm{CO}_{2}$ mediated anxiety and hypertension (Johnson et al., 2012a). Exposing rats to higher concentrations of hypercarbic gas (e.g., $20 \% \mathrm{CO}_{2}$ ) depolarizes OX neurons by interacting with $\mathrm{pH} / \mathrm{CO}_{2}$ chemosensitive $\mathrm{K}^{+}$channels (Williams et al., 2007), and also causes subsequent release of orexin at post-synaptic targets in the brain and spinal cord to mobilize anxietylike behavior, hypertension, and increases ventilatory responses (Johnson et al., 2012c, 2015). JNJ-54717793 was tested in a rat model of $\mathrm{CO}_{2}$-induced panic. JNJ-54717793 had no effect on baseline cardiovascular activity (see t- 5 to t- 1 on Figures 4 A,B). The $30 \mathrm{mg} / \mathrm{kg}$ dose of JNJ-54717793 attenuated $\mathrm{CO}_{2}$-induced pressor responses at multiple time points $(3 \mathrm{mg} / \mathrm{kg}$ at one time point) [treatment $\times$ time interaction $F(56,462)=4.5$, $p<0.001, n=7,7,8,8,8 /$ group, Figure 4A]. The 10 and $30 \mathrm{mg} / \mathrm{kg}$ dose of JNJ-54717793 attenuated $\mathrm{CO}_{2}$-induced bradycardia responses at multiple time points [treatment $\times$ time interaction $F(56,462)=8.8, p<0.001, n=7,7,8,8,8$ /group, Figure 4B]. Although JNJ-54717793 had no effect on increases in locomotor activity post $\mathrm{CO}_{2}$ (Figure $4 \mathrm{C}$ ), the highest dose attenuated/blocked $\mathrm{CO}_{2}$-induced anxiety behavior in the SI test $[F(3,38)=3.5, p=0.016, n=7,7,8,8,8$, Figure 4D] with no apparent sedative effects (line crossings) in the open field test $[F(4,36)=1.8, p=0.150, n=7,7,8,8,8$, Figure $4 \mathrm{E}]$. Nor was there an effect on center or middle times $[F(4,36)=0.8, p=0.512$, and $F(4,36)=1.7, p=0.167$, respectively] 


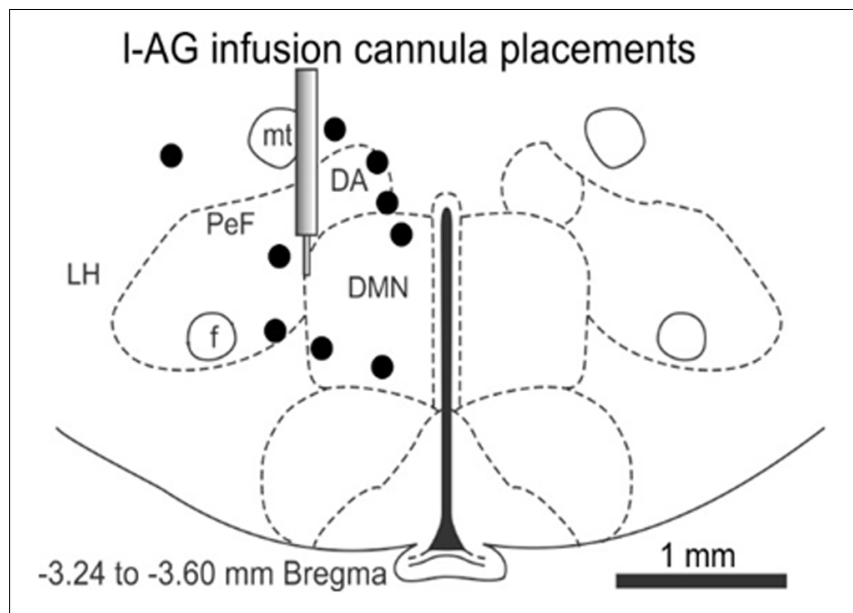

FIGURE 5 | In the 1-allyglycine (I-AG) panic vulnerability model experiment, this illustration shows a representative coronal brain section of the hypothalamus at $-3.24 \mathrm{~mm}$ from Bregma taken from a Standard Stereotaxic Rat Brain Atlas (Paxinos and Watson, 2005) with circles depicting unilateral cannula placements and infusions of 1-allyglycine (a GABA synthesis inhibitor) that were distributed from -3.24 to $-6.70 \mathrm{~mm}$ from Bregma and located in the perifornical and dorsomedial hypothalamic region or within $\leq 0.3 \mathrm{~mm}$ from those regions. The illustration of the guide cannula depicts the target region for cannula placements. 1-AG, 1-allyglycine; DA, anterior dorsomedial nucleus of the hypothalamus; DMN, dorsomedial nucleus of the hypothalamus; $f$, fornix; LH, lateral hypothalamus; mt, mammillothalamic fiber tract; PeF, perifornical hypothalamic area.

\section{Effect of JNJ-54717793 in a Model of NaLac Induced Panic}

The effect of JNJ-54717793 was investigated in a model of panic vulnerability where chronic disinhibition of the perifornical hypothalamic area orexin region leads to exacerbated panic responses to a well-known interoceptive panicogenic challenge (i.e., sodium lactate). The 1-allyglycine infusion cannula placements were all located within the perifornical and dorsomedial hypothalamic area from -3.24 to -3.60 in a distribution consistent with prior 1-allyglycine studies in this panic model (Johnson and Shekhar, 2006; Shekhar et al., 2006, 2011; Johnson et al., 2008, 2010, 2012b) (Figure 5), and also in close proximity to orexin neuron distributions that are located from -2.64 to $-3.60 \mathrm{~mm}$ from Bregma (Peyron et al., 1998).

JNJ-54717793 had no effect on baseline cardiovascular activity (see t-5 to t-1 on Figures $6 A, B$ ). Although there was no treatment $\times$ time or overall treatment effect $[F(3,29)=2.8$, $p=0.090]$ detected, an individual ANOVA with post hoc test at the $\mathrm{t} 3$ timepoint revealed an attenuation of pressor response with the $10 \mathrm{mg} / \mathrm{kg}$ dose of JNJ-54717793 $[F(3,32)=3.3, p=0.034$, $n=7,8,10,8$, Figure $6 \mathrm{~A}]$. Compared to the vehicle group JNJ54717793 did not attenuate sodium lactate-induced tachycardia [treatment $\times$ time interaction $F(57,570)=0.9, p=0.780$, $n=7,8,10,9$, Figure 6B]. JNJ-54717793 did not significantly alter locomotion [treatment $\times$ time interaction, $F(57,608)=0.6$, $p=0.987, n=8,9,10,9$, Figure $6 \mathbf{D}]$, but the sodium lactate also did not significantly increase locomotion $[F(3,32)=0.1$, $p=0.934]$. Although JNJ-54717793 had minimal effects on cardioexcitation, the highest dose did attenuate/block sodium lactate-induced anxiety behavior in the SI test $[F(4,40)=5.1$, $p=0.002, n=8,9,10,9$, Figure $6 \mathrm{C}]$ with no apparent sedative effects (line crossings) in the open field test $[F(4,54)=1.9$, $p=0.128, n=11 /$ group, Figure 6E]. Nor was there an effect on center or middle times $[F(4,54)=0.9, p=0.490$ and $F(4,54)=1.2, p=0.340$, respectively]. The unequal n's/per group were due to video malfunctions or complications with radiotelemetry data acquisition.

\section{DISCUSSION}

In the present study we initially determined that JNJ-54717793 is a high affinity, potent and selective OX1R antagonist. After systemic administration JNJ-54717793 crossed the blood brain barrier, occupied OX1Rs in the rat brain and minimally affected spontaneous sleep. We then utilized two different panic models (i.e., threshold panic induction with $20 \% \mathrm{CO}_{2}$ exposure in normal rats and subthreshold panic induction with intravenous sodium lactate infusion in panic-prone rats), and demonstrated that pretreatment with JNJ-54717793 attenuated $\mathrm{CO}_{2}$ and sodium lactate induced panic-like behaviors and cardiovascular responses without altering baseline locomotor or autonomic activity. These data are consistent with previous reports of selective OX1R antagonists attenuating $\mathrm{CO}_{2}$ and sodium lactate induced panic-associated behavior and cardiorespiratory responses (Dias et al., 2010; Johnson et al., 2010, 2012d, 2015; Bonaventure et al., 2015b) with little effect on sleep-wake states (Dugovic et al., 2014). In contrast, benzodiazepines are also panicolytic in these models, but do reduce locomotor activity at panicolytic doses (Bonaventure et al., 2015b; Johnson et al., 2015), which is consistent with sedative effects being a significant side effect clinically (Charney and Heninger, 1985; Tesar and Rosenbaum, 1986; Ballenger et al., 1988). In the $20 \% \mathrm{CO}_{2}$ model, a dual orexin receptor antagonist (i.e., DORA-12) has also been shown to attenuate some aspects of the panic response, but this appears to be primarily through the OX1R and not OX2R since a highly selective and brain penetrant OX2R antagonist (JNJ-10397049) did not alter panic responses to $20 \% \mathrm{CO}_{2}$ (Bonaventure et al., 2015b; Johnson et al., 2015). In other stress paradigms, both selective OX1R antagonists and selective OX2R antagonists have been shown to have anxiolytic/panicolytic effects. For instance, both OX1R and OX2R contribute to cardiorespiratory responses post-perifornical hypothalamic area disinhibition (Beig et al., 2015b), and both the OX1R antagonist ACT335827 and the selective OX2R antagonist EMPA attenuate novelty stress (cage changes) induced cardioexcitation (Beig et al., 2015a). Yet, like benzodiazepines, selective OX2R antagonists induce and prolong sleep in rodents (Dugovic et al., 2009; Mang et al., 2012; Bonaventure et al., 2015a), thus making them less ideal than selective OX1R antagonists. Collectively, these results and previous data suggest that selective OX1R antagonists may represent a novel approach of treating anxiety disorders, without sedative effects.

Both panic models used here induce significant increases in ex vivo cellular c-Fos activity within brain circuits strongly 

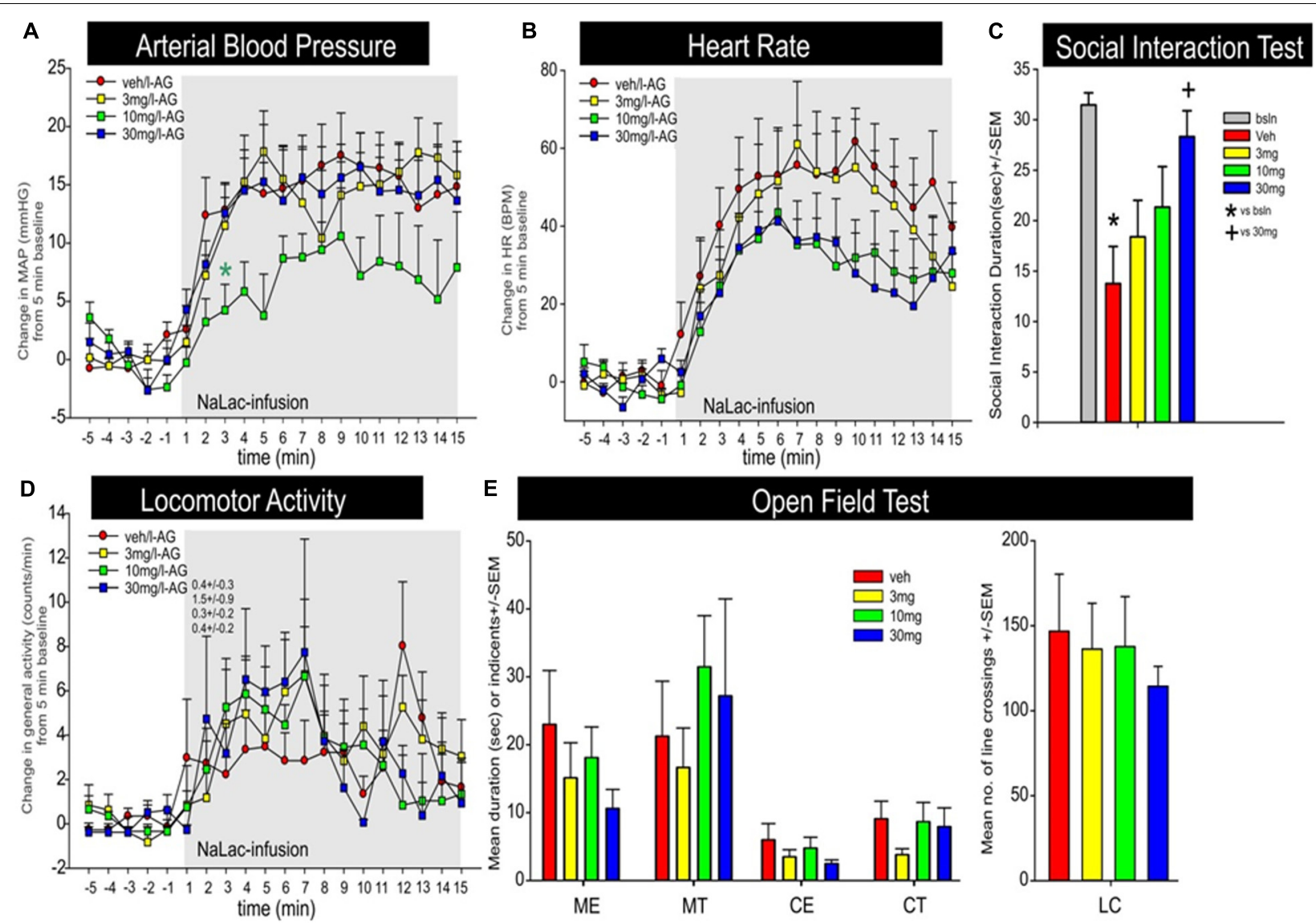

FIGURE 6 | Effect of JNJ-54717793 in a model of sodium lactate induced panic. Line graphs indicate the effects of oral gavage (p.o.) of vehicle, or 3, 10, or $30 \mathrm{mg} / \mathrm{kg}$ doses of JNJ-54717793 on intravenous sodium lactate (NaLac) induced changes (from 5 min baseline) in (A) mean arterial blood pressure (MAP, mm Hg), (B) HR [beats/min (BPM)], and (D) general locomotor activity (counts/min) in freely moving rats surgically implanted with radiotelemetry probes. There were no significant differences in baseline MAP, HR, or locomotor activity (t-5 to t-1 minute). Gray shaded area represents the NaLac infusions. * Indicates between subjects differences using a Fisher's LSD post hoc test that was protected with a repeated measures ANOVA and an ANOVA at each time point, $p<0.05$. Bar graphs indicate the effects of JNJ-54717793 on NaLac induced changes in (C) SI in the SI test, and (E) line crossings and middle and center time in the open field test. * and + respectively indicate between subjects differences between baseline and veh/NaLac or veh/NaLac and 30 mg/kg JNJ-54717793/NaLac using a Fisher's LSD post hoc test that was protected with an ANOVA, $p<0.05$.

implicated in innate panic (and associated with panic attacks), and in the panic vulnerability model there is also increase in activity within fear associated learning centers (and associated with strong phobia comorbidity with recurrent panic attacks). In the $20 \% \mathrm{CO}_{2}$ model in naïve rats, panic responses are associated with increases in cellular activity within the perifornical hypothalamic area orexin neurons and cardiorespiratory brainstem circuits (Johnson et al., 2005, 2011, 2012d). In the sodium lactate model, there are additional increases in cellular responses within the amygdala and bed nucleus of the stria terminalis (Johnson et al., 2008). Although orexin neurons innervate many brain regions, they are particularly dense in these brain regions that are mobilized in innate panic and learned fear response (Peyron et al., 1998; Nambu et al., 1999). These include noradrenergic locus coeruleus, and serotonergic systems in midbrain raphe which are current therapeutic targets for treating anxiety disorders, brainstem cardiorespiratory nuclei and bed nucleus of the stria terminalis and amygdala. In many brain regions both OX1R and OX2R receptors are significantly expressed (Trivedi et al., 1998; Marcus et al., 2001). Yet in other regions the expression is more limited to the OX1R or OX2R. For instance, histaminergic neurons in the tuberomamillary nucleus (TMN) have high expression of the OX2R and almost undetectable expression of the OX1R (Eriksson et al., 2001; Marcus et al., 2001). The TMN plays a critical role in wake promotion (Bayer et al., 2001; Huang et al., 2001) and the OX2R on TMN neurons is a major target for wake promoting properties of OX neurons. Conversely, OX1R have a higher expression within the limbic systems (bed nucleus of the stria terminalis and amygdala), cingulate cortex, and noradrenergic locus coeruleus. Accordingly, the functional significance is that OX2R antagonists have potent sleep promoting effects (Bonaventure et al., 2015a; Gotter et al., 2016), which are not apparent with OX1R antagonists (Bonaventure et al., 2015b). Pretreating rats with an OX1R antagonist prior to administering a panicogenic drug (i.e., FG-7142) blocks FG-7142 induced increases in cellular 
activity in innate panic and learned fear brain circuits that have higher expression of OX1R versus OX2R (e.g., amygdala and dorsal periaqueductal gray and sympathetic nuclei) (Johnson et al., 2012c). Taken together, the panicolytic effects of the OX1R antagonist used here lends further support that OX1R antagonists may be more effective than OX2R antagonists for treating anxiety and fear associated disorders in the absence of sedative effects.

Although the orexin system and OX1Rs appear to be a novel therapeutic target for treating anxiety symptoms/disorders, it is important to note that orexin and orexin receptors may not be involved in all stress responses. For instance, in addition to $\mathrm{CO}_{2}$ and sodium lactate challenges, OX neurons are activated during arousal, exploration and footshock stress, but not by restraint or cold exposure stress (Furlong et al., 2009). Furthermore, in these same studies the dual orexin receptor antagonist almorexant attenuated locomotor and cardiovascular responses to exploration and footshock, but not to restraint or cold stress. In mild stress paradigms, OX1R antagonists also do not alter anxiety-associated avoidance behavior in the elevated plus maze test or SI test (Yeoh et al., 2014). Yet, in more aversive stress paradigms, OX1R antagonists do reduce anxiety/fear-associated behaviors in the fear conditioned startle and in resident intruder tests (Steiner et al., 2012, 2013). In other stress paradigms both receptors are involved. Specifically, systemic administration of selective antagonist at OX1R (ACT335827) or at OX2R (EMPA) attenuates novelty stress (cage changes) induced cardioexcitation (Beig et al., 2015a), and both OX1R and OX2R contribute to cardiorespiratory responses post-perifornical hypothalamic area disinhibition (Beig et al., 2015b).

Orexin receptor antagonists have also been implicated in attenuation of fear-associated learning. For instance, in a cue induced fear conditioning paradigm, Sears et al. (2013) reported that OX enhances fear acquisition via OX1Rs and not OX2Rs and through a locus coeruleus-amygdala pathway. This is consistent with a study showing that systemic administration of OX1R, but not OX2R antagonists also attenuate freezing following contextual fear conditioning (Wang et al., 2017), and another study demonstrating that following cue or contextual fear conditioning, systemic or intra-amygdala administration of an OX1R antagonist enhanced extinction, and intracebral infusions of OXA impaired extinction (Flores et al., 2014). Yet, in this study administration of an OX2R antagonist did enhance contextual fear extinction while the orexin-B administration had no effect. Pro fear circuits such as the central amygdala and locus coeruleus are moderately and densely innervated

\section{REFERENCES}

Abshire, V. M., Hankins, K. D., Roehr, K. E., and DiMicco, J. A. (1988). Injection of L-allylglycine into the posterior hypothalamus in rats causes decreases in local GABA which correlate with increases in heart rate. Neuropharmacology 27, 1171-1177. doi: 10.1016/0028-3908(88)90013-5

Anderson, J. J., and DiMicco, J. A. (1990). Effect of local inhibition of gammaaminobutyric acid uptake in the dorsomedial hypothalamus on extracellular levels of gamma-aminobutyric acid and on stress-induced tachycardia: a study using microdialysis. J. Pharmacol. Exp. Ther. 255, 1399-1407. by orexin neurons, respectively (Peyron et al., 1998) with the amygdala expressing more OX1R than OX2R and the locus coeruleus expressing exclusively OX1R (Marcus et al., 2001).

\section{CONCLUSION}

Although OX1R antagonists may not alleviate mild anxiety or all anxiety associated symptoms they do appear to be effective in rapidly reducing panic and fear associated responses in most stress paradigms, especially as they become more severe, without sedation side effects that would be associated with OX2R antagonists or fast acting panicolytic benzodiazepines (Nutt et al., 2002; Baldwin et al., 2005; Bandelow et al., 2008; Cloos and Ferreira, 2009). OX1R antagonists also have an advantage over SSRIs which become effective 2-3 weeks after daily use (Pollack et al., 2007a,b) and tend to increase anxiety symptoms initially both clinically (Goddard et al., 2001) and preclinically (Ravinder et al., 2013).

\section{AUTHOR CONTRIBUTIONS}

Participated in research design: PB, PJ, AS, TL, CD; conducted experiments: SY, SF, DN, BL, MW; contributed new reagents or analytic tools: BS, CP, NC; performed data analysis: $\mathrm{PB}, \mathrm{PJ}, \mathrm{DN}$, $\mathrm{BL}, \mathrm{CD}$; wrote or contributed to the writing of the manuscript: PB, PJ, CD.

\section{FUNDING}

PB, CD, BS, SY, CP, BL, DN, NC, and TL are paid employees at Janssen Research and Development, LLC. This work was supported by a NIA K01AG044466, and a pilot grant from NIH UL1 RR025761 (Shekhar, PI), to PJ, and NIMH R01 MH52619, and R01 MH65702 to AS.

\section{ACKNOWLEDGMENT}

The assistance of Drs Kevin Sharp and Tatiana Koudriakova and their staff at Janssen Research \& Development, LLC (San Diego, CA, United States) is gratefully acknowledged.

Baldwin, D. S., Anderson, I. M., Nutt, D. J., Bandelow, B., Bond, A., Davidson, J. R., et al. (2005). Evidence-based guidelines for the pharmacological treatment of anxiety disorders: recommendations from the British Association for Psychopharmacology. J. Psychopharmacol. 19, 567-596. doi: 10.1177/ 0269881105059253

Ballenger, J. C., Burrows, G. D., DuPont, R. L. Jr., Lesser, I. M., Noyes, R. Jr., Pecknold, J. C., et al. (1988). Alprazolam in panic disorder and agoraphobia: results from a multicenter trial. I. Efficacy in short-term treatment. Arch. Gen. Psychiatry 45, 413-422. doi: 10.1001/archpsyc.1988.018002900 27004 
Bandelow, B., Zohar, J., Hollander, E., Kasper, S., Moller, H. J., Allgulander, C., et al. (2008). World Federation of Societies of Biological Psychiatry (WFSBP) guidelines for the pharmacological treatment of anxiety, obsessive-compulsive and post-traumatic stress disorders - first revision. World J. Biol. Psychiatry 9, 248-312. doi: 10.1080/15622970802465807

Bayer, L., Eggermann, E., Serafin, M., Saint-Mleux, B., Machard, D., Jones, B., et al. (2001). Orexins (hypocretins) directly excite tuberomammillary neurons. Eur. J. Neurosci. 14, 1571-1575. doi: 10.1046/j.0953-816x.2001. 01777.x

Beig, M. I., Dampney, B. W., and Carrive, P. (2015a). Both Ox1r and Ox2r orexin receptors contribute to the cardiovascular and locomotor components of the novelty stress response in the rat. Neuropharmacology 89, 146-156. doi: 10. 1016/j.neuropharm.2014.09.012

Beig, M. I., Horiuchi, J., Dampney, R. A., and Carrive, P. (2015b). Both Ox1R and $\mathrm{Ox} 2 \mathrm{R}$ orexin receptors contribute to the cardiorespiratory response evoked from the perifornical hypothalamus. Clin. Exp. Pharmacol. Physiol. 42, 10591067. doi: $10.1111 / 1440-1681.12461$

Bonaventure, P., Shelton, J., Yun, S., Nepomuceno, D., Sutton, S., Aluisio, L., et al. (2015a). Characterization of JNJ-42847922, a selective orexin-2 receptor antagonist, as a clinical candidate for the treatment of insomnia. J. Pharmacol. Exp. Ther. 354, 471-482. doi: 10.1124/jpet.115.225466

Bonaventure, P., Yun, S., Johnson, P. L., Shekhar, A., Fitz, S. D., Shireman, B. T., et al. (2015b). A selective orexin-1 receptor antagonist attenuates stress-induced hyperarousal without hypnotic effects. J. Pharmacol. Exp. Ther. 352, 590-601. doi: 10.1124/jpet.114.220392

Bonnavion, P., Jackson, A. C., Carter, M. E., and de Lecea, L. (2015). Antagonistic interplay between hypocretin and leptin in the lateral hypothalamus regulates stress responses. Nat. Commun. 6:6266. doi: 10.1038/ncomms7266

Boss, C., and Roch, C. (2015). Recent trends in orexin research-2010 to 2015. Bioorg. Med. Chem. Lett. 25, 2875-2887. doi: 10.1016/j.bmcl.2015.05.012

Charney, D. S., and Heninger, G. R. (1985). Noradrenergic function and the mechanism of action of antianxiety treatment. II. The effect of long-term imipramine treatment. Arch. Gen. Psychiatry 42, 473-481. doi: 10.1001/ archpsyc.1985.01790280055005

Cheng, Y., and Prusoff, W. H. (1973). Relationship between the inhibition constant (K1) and the concentration of inhibitor which causes 50 per cent inhibition (I50) of an enzymatic reaction. Biochem. Pharmacol. 22, 3099-3108. doi: 10. 1016/0006-2952(73)90196-2

Cloos, J. M., and Ferreira, V. (2009). Current use of benzodiazepines in anxiety disorders. Curr. Opin. Psychiatry 22, 90-95. doi: 10.1097/YCO. 0b013e32831a473d

de Beurs, E., Garssen, B., Buikhuisen, M., Lange, A., van Balkom, A., and Van Dyck, R. (1994). Continuous monitoring of panic. Acta Psychiatr. Scand. 90, 38-45. doi: 10.1111/j.1600-0447.1994.tb01553.x

Desarnaud, F., Murillo-Rodriguez, E., Lin, L., Xu, M., Gerashchenko, D., Shiromani, S. N., et al. (2004). The diurnal rhythm of hypocretin in young and old F344 rats. Sleep 27, 851-856. doi: 10.1093/sleep/ 27.5.851

Dias, M. B., Li, A., and Nattie, E. (2010). The orexin receptor 1 (OX1R) in the rostral medullary raphe contributes to the hypercapnic chemoreflex in wakefulness, during the active period of the diurnal cycle. Respir. Physiol. Neurobiol. 170, 96-102. doi: 10.1016/j.resp.2009.12.002

Dugovic, C., Shelton, J. E., Aluisio, L. E., Fraser, I. C., Jiang, X., Sutton, S. W., et al. (2009). Blockade of orexin-1 receptors attenuates orexin-2 receptor antagonism-induced sleep promotion in the rat. J. Pharmacol. Exp. Ther. 330, 142-151. doi: 10.1124/jpet.109.152009

Dugovic, C., Shelton, J. E., Yun, S., Bonaventure, P., Shireman, B. T., and Lovenberg, T. W. (2014). Orexin-1 receptor blockade dysregulates REM sleep in the presence of orexin-2 receptor antagonism. Front. Neurosci. 8:28. doi: 10.3389/fnins.2014.00028

Eriksson, K. S., Sergeeva, O., Brown, R. E., and Haas, H. L. (2001). Orexin/hypocretin excites the histaminergic neurons of the tuberomammillary nucleus. J. Neurosci. 21, 9273-9279.

Flores, A., Saravia, R., Maldonado, R., and Berrendero, F. (2015). Orexins and fear: implications for the treatment of anxiety disorders. Trends Neurosci. 38, 550-559. doi: 10.1016/j.tins.2015.06.005

Flores, A., Valls-Comamala, V., Costa, G., Saravia, R., Maldonado, R., and Berrendero, F. (2014). The hypocretin/orexin system mediates the extinction of fear memories. Neuropsychopharmacology 39, 2732-2741. doi: 10.1038/npp. 2014.146

Forsyth, J. P., Eifert, G. H., and Canna, M. A. (2000). Evoking analogue subtypes of panic attacks in a nonclinical population using carbon dioxideenriched air. Behav. Res. Ther. 38, 559-572. doi: 10.1016/S0005-7967(99) 00074-1

Furlong, T. M., Vianna, D. M., Liu, L., and Carrive, P. (2009). Hypocretin/orexin contributes to the expression of some but not all forms of stress and arousal. Eur. J. Neurosci. 30, 1603-1614. doi: 10.1111/j.1460-9568.2009. 06952.x

Goddard, A. W., Brouette, T., Almai, A., Jetty, P., Woods, S. W., and Charney, D. (2001). Early coadministration of clonazepam with sertraline for panic disorder. Arch. Gen. Psychiatry 58, 681-686. doi: 10.1001/archpsyc.58. 7.681

Gorman, J. M., Papp, L. A., Coplan, J. D., Martinez, J. M., Lennon, S., Goetz, R. R., et al. (1994). Anxiogenic effects of $\mathrm{CO}_{2}$ and hyperventilation in patients with panic disorder. Am. J. Psychiatry 151, 547-553. doi: 10.1176/ajp. 151.4.547

Gotter, A. L., Forman, M. S., Harrell, C. M., Stevens, J., Svetnik, V., Yee, K. L., et al. (2016). Orexin 2 receptor antagonism is sufficient to promote NREM and REM sleep from mouse to man. Sci. Rep. 6:27147. doi: 10.1038/srep 27147

Gozzi, A., Lepore, S., Vicentini, E., Merlo-Pich, E., and Bifone, A. (2013). Differential effect of orexin-1 and CRF-1 antagonism on stress circuits: a fMRI study in the rat with the pharmacological stressor Yohimbine. Neuropsychopharmacology 38, 2120-2130. doi: 10.1038/npp.2013.109

Heydendael, W., Sengupta, A., Beck, S., and Bhatnagar, S. (2013). Optogenetic examination identifies a context-specific role for orexins/hypocretins in anxiety-related behavior. Physiol. Behav. 130, 182-190. doi: 10.1016/j.physbeh. 2013.10.005

Hickman, D. L., Fitz, S. D., Bernabe, C. S., Caliman, I. F., Haulcomb, M. M., Federici, L. M., et al. (2016). Evaluation of low versus high volume per minute displacement $\mathrm{CO}_{2}$ methods of euthanasia in the induction and duration of panic-associated behavior and physiology. Animals 6:E45. doi: 10.3390/ ani6080045

Huang, Z. L., Qu, W. M., Li, W. D., Mochizuki, T., Eguchi, N., Watanabe, T., et al. (2001). Arousal effect of orexin A depends on activation of the histaminergic system. Proc. Natl. Acad. Sci. U.S.A. 98, 9965-9970. doi: 10.1073/ pnas. 181330998

Johnson, P. L., Federici, L. M., Fitz, S. D., Renger, J. J., Shireman, B., Winrow, C. J., et al. (2015). Orexin 1 and 2 receptor involvement in $\mathrm{CO}_{2}$-induced panicassociated behavior and autonomic responses. Depress. Anxiety 32, 671-683. doi: $10.1002 /$ da.22403

Johnson, P. L., Fitz, S. D., Engleman, E. A., Svensson, K. A., Schkeryantz, J. M., and Shekhar, A. (2012b). Group II metabotropic glutamate receptor type 2 allosteric potentiators prevent sodium lactate-induced panic-like response in panic-vulnerable rats. J. Psychopharmacol. 27, 152-161. doi: 10.1177/ 0269881112454230

Johnson, P. L., Fitz, S. D., Hollis, J. H., Moratalla, R., Lightman, S. L., Shekhar, A., et al. (2011). Induction of c-Fos in 'panic/defence'-related brain circuits following brief hypercarbic gas exposure. J. Psychopharmacol. 25, 26-36. doi: $10.1177 / 0269881109353464$

Johnson, P. L., Hollis, J. H., Moratalla, R., Lightman, S. L., and Lowry, C. A. (2005). Acute hypercarbic gas exposure reveals functionally distinct subpopulations of serotonergic neurons in rats. J. Psychopharmacol. 19, 327-341. doi: 10.1177/ 0269881105053281

Johnson, P. L., Molosh, A., Fitz, S. D., Truitt, W. A., and Shekhar, A. (2012a). Orexin, stress, and anxiety/panic states. Prog. Brain Res. 198, 133-161. doi: 10.1016/B978-0-444-59489-1.00009-4

Johnson, P. L., Samuels, B. C., Fitz, S. D., Federici, L. M., Hammes, N., Early, M. C., et al. (2012c). Orexin 1 receptors are a novel target to modulate panic responses and the panic brain network. Physiol. Behav. 107, 733-742. doi: 10.1016/j.physbeh.2012.04.016

Johnson, P. L., Samuels, B. C., Fitz, S. D., Lightman, S. L., Lowry, C. A., and Shekhar, A. (2012d). Activation of the orexin 1 receptor is a critical component of $\mathrm{CO} 2$-mediated anxiety and hypertension but not bradycardia. Neuropsychopharmacology 37, 1911-1922. doi: 10.1038/npp. 2012.38 
Johnson, P. L., and Shekhar, A. (2006). Panic-prone state induced in rats with GABA dysfunction in the dorsomedial hypothalamus is mediated by NMDA receptors. J. Neurosci. 26, 7093-7104. doi: 10.1523/JNEUROSCI.0408-06. 2006

Johnson, P. L., and Shekhar, A. (2012). An animal model of panic vulnerability with chronic disinhibition of the dorsomedial/perifornical hypothalamus. Physiol. Behav. 107, 686-698. doi: 10.1016/j.physbeh.2012.03.016

Johnson, P. L., Truitt, W., Fitz, S. D., Minick, P. E., Dietrich, A., Sanghani, S., et al. (2010). A key role for orexin in panic anxiety. Nat. Med. 16, 111-115. doi: $10.1038 / \mathrm{nm} .2075$

Johnson, P. L., Truitt, W. A., Fitz, S. D., Lowry, C. A., and Shekhar, A. (2008). Neural pathways underlying lactate-induced panic. Neuropsychopharmacology 33, 2093-2107. doi: 10.1038/sj.npp.1301621

Kuwaki, T., Zhang, W., Nakamura, A., and Deng, B. S. (2008). Emotional and state-dependent modification of cardiorespiratory function: role of orexinergic neurons. Auton. Neurosci. 142, 11-16. doi: 10.1016/j.autneu.2008. 03.004

Langmead, C. J., Jerman, J. C., Brough, S. J., Scott, C., Porter, R. A., and Herdon, H. J. (2004). Characterisation of the binding of [3H]-SB-674042, a novel nonpeptide antagonist, to the human orexin-1 receptor. Br. J. Pharmacol. 141, 340-346. doi: 10.1038/sj.bjp.0705610

Malherbe, P., Borroni, E., Gobbi, L., Knust, H., Nettekoven, M., Pinard, E., et al. (2009). Biochemical and behavioural characterization of EMPA, a novel high-affinity, selective antagonist for the $\mathrm{OX}_{2}$ receptor. Br. J. Pharmacol. 156, 1326-1341. doi: 10.1111/j.1476-5381.2009.00127.x

Mang, G. M., Durst, T., Burki, H., Imobersteg, S., Abramowski, D., Schuepbach, E., et al. (2012). The dual orexin receptor antagonist almorexant induces sleep and decreases orexin-induced locomotion by blocking orexin 2 receptors. Sleep 35 , 1625-1635. doi: 10.5665/sleep. 2232

Marcus, J. N., Aschkenasi, C. J., Lee, C. E., Chemelli, R. M., Saper, C. B., Yanagisawa, M., et al. (2001). Differential expression of orexin receptors 1 and 2 in the rat brain. J. Comp. Neurol. 435, 6-25. doi: 10.1002/cne. 1190

Mignot, E., Lammers, G. J., Ripley, B., Okun, M., Nevsimalova, S., Overeem, S., et al. (2002). The role of cerebrospinal fluid hypocretin measurement in the diagnosis of narcolepsy and other hypersomnias. Arch. Neurol. 59, 1553-1562. doi: 10.1001/archneur.59.10.1553

Nambu, T., Sakurai, T., Mizukami, K., Hosoya, Y., Yanagisawa, M., and Goto, K. (1999). Distribution of orexin neurons in the adult rat brain. Brain Res. 827, 243-260. doi: 10.1016/S0006-8993(99)01336-0

Nutt, D. J., Ballenger, J. C., Sheehan, D., and Wittchen, H. U. (2002). Generalized anxiety disorder: comorbidity, comparative biology and treatment. Int. J. Neuropsychopharmacol. 5, 315-325. doi: 10.1017/S146114570200 3048

Paxinos, G., and Watson, C. (2005). The Rat Brain in Stereotaxic Coordinates. San Diego, CA: Elsevier.

Peyron, C., Tighe, D. K., van den Pol, A. N., de Lecea, L., Heller, H. C., Sutcliffe, J. G., et al. (1998). Neurons containing hypocretin (orexin) project to multiple neuronal systems. J. Neurosci. 18, 9996-10015.

Pitts, F. N. Jr., and McClure, J. N. Jr. (1967). Lactate metabolism in anxiety neurosis. N. Engl. J. Med. 277, 1329-1336. doi: 10.1056/NEJM19671221277 2502

Pollack, M., Mangano, R., Entsuah, R., Tzanis, E., Simon, N. M., and Zhang, Y. (2007a). A randomized controlled trial of venlafaxine ER and paroxetine in the treatment of outpatients with panic disorder. Psychopharmacology 194, 233-242.

Pollack, M. H., Lepola, U., Koponen, H., Simon, N. M., Worthington, J. J., Emilien, G., et al. (2007b). A double-blind study of the efficacy of venlafaxine extended-release, paroxetine, and placebo in the treatment of panic disorder. Depress. Anxiety 24, 1-14. doi: 10.1002/da.20218

Rasche, D., Foethke, D., Gliemroth, J., and Tronnier, V. M. (2006). Deep brain stimulation in the posterior hypothalamus for chronic cluster headache. Case report and review of the literature. Schmerz 20, 439-444. doi: 10.1007/s00482005-0462-3

Ravinder, S., Burghardt, N. S., Brodsky, R., Bauer, E. P., and Chattarji, S. (2013). A role for the extended amygdala in the fear-enhancing effects of acute selective serotonin reuptake inhibitor treatment. Transl. Psychiatry 3:e209. doi: 10.1038/ tp.2012.137
Samuels, B. C., Zaretsky, D. V., and DiMicco, J. A. (2002). Tachycardia evoked by disinhibition of the dorsomedial hypothalamus in rats is mediated through medullary raphe. J. Physiol 538(Pt 3), 941-946. doi: 10.1113/jphysiol.2001. 013302

Sanders, S. K., and Shekhar, A. (1995). Regulation of anxiety by GABAA receptors in the rat amygdala. Pharmacol. Biochem. Behav. 52, 701-706. doi: 10.1016/ 0091-3057(95)00153-N

Sears, R. M., Fink, A. E., Wigestrand, M. B., Farb, C. R., de Lecea, L., and Ledoux, J. E. (2013). Orexin/hypocretin system modulates amygdala-dependent threat learning through the locus coeruleus. Proc. Natl. Acad. Sci. U.S.A. 110, 20260-20265. doi: 10.1073/pnas.1320325110

Shekhar, A., and DiMicco, J. A. (1987). Defense reaction elicited by injection of GABA antagonists and synthesis inhibitors into the posterior hypothalamus in rats. Neuropharmacology 26, 407-417. doi: 10.1016/0028-3908(87) 90020-7

Shekhar, A., Hingtgen, J. N., and DiMicco, J. A. (1990). GABA receptors in the posterior hypothalamus regulate experimental anxiety in rats. Brain Res. 512, 81-88. doi: 10.1016/0006-8993(90)91173-E

Shekhar, A., Johnson, P. L., Fitz, S. D., Nakazato, A., Chaki, S., Steckler, T., et al. (2011). A selective, non-peptide CRF receptor 1 antagonist prevents sodium lactate-induced acute panic-like responses. Int. J. Neuropsychopharmacol. 14, 355-365. doi: 10.1017/S1461145710001355

Shekhar, A., Johnson, P. L., Sajdyk, T. J., Fitz, S. D., Keim, S. R., Kelley, P. E., et al. (2006). Angiotensin-II is a putative neurotransmitter in lactateinduced panic-like responses in rats with disruption of GABAergic inhibition in the dorsomedial hypothalamus. J. Neurosci. 26, 9205-9215. doi: 10.1523/ JNEUROSCI.2491-06.2006

Shekhar, A., and Katner, J. S. (1995). Dorsomedial hypothalamic GABA regulates anxiety in the social interaction test. Pharmacol. Biochem. Behav. 50, 253-258. doi: 10.1016/0091-3057(94)00307-5

Shekhar, A., and Keim, S. R. (1997). The circumventricular organs form a potential neural pathway for lactate sensitivity: implications for panic disorder. J. Neurosci. 17, 9726-9735.

Shekhar, A., Keim, S. R., Simon, J. R., and McBride, W. J. (1996). Dorsomedial hypothalamic GABA dysfunction produces physiological arousal following sodium lactate infusions. Pharmacol. Biochem. Behav. 55, 249-256. doi: 10. 1016/S0091-3057(96)00077-9

Soltis, R. P., and DiMicco, J. A. (1992). Hypothalamic excitatory amino acid receptors mediate stress-induced tachycardia in rats. Am. J. Physiol. 262(4 Pt 2), R689-R697.

Steiner, M., Lecourt, H., and Jenck, F. (2012). The brain orexin system and almorexant in fear-conditioned startle reactions in the rat. Psychopharmacology 223, 465-475. doi: 10.1007/s00213-012-2736-7

Steiner, M. A., Gatfield, J., Brisbare-Roch, C., Dietrich, H., Treiber, A., Jenck, F., et al. (2013). Discovery and characterization of ACT-335827, an orally available, brain penetrant orexin receptor type 1 selective antagonist. ChemMedChem 8 , 898-903. doi: 10.1002/cmdc.201300003

Suzuki, M., Beuckmann, C. T., Shikata, K., Ogura, H., and Sawai, T. (2005). Orexin-A (hypocretin-1) is possibly involved in generation of anxiety-like behavior. Brain Res. 1044, 116-121. doi: 10.1016/j.brainres.2005. 03.002

Tesar, G. E., and Rosenbaum, J. F. (1986). Successful use of clonazepam in patients with treatment-resistant panic disorder. J. Nerv. Ment. Dis. 174, 477-482. doi: 10.1097/00005053-198608000-00006

Thannickal, T. C., Lai, Y. Y., and Siegel, J. M. (2007). Hypocretin (orexin) cell loss in Parkinson's disease. Brain 130(Pt 6), 1586-1595. doi: 10.1093/brain/ awm097

Trivedi, P., Yu, H., MacNeil, D. J., Van der Ploeg, L. H., and Guan, X. M. (1998). Distribution of orexin receptor mRNA in the rat brain. FEBS Lett. 438, 71-75. doi: 10.1016/S0014-5793(98)01266-6

Wang, H., Li, S., and Kirouac, G. J. (2017). Role of the orexin (hypocretin) system in contextual fear conditioning in rats. Behav. Brain Res. 316, 47-53. doi: 10.1016/j.bbr.2016.08.052

Wilent, W. B., Oh, M. Y., Buetefisch, C., Bailes, J. E., Cantella, D., Angle, C., et al. (2011). Mapping of microstimulation evoked responses and unit activity patterns in the lateral hypothalamic area recorded in awake humans. Technical note. J. Neurosurg. 115, 295-300. doi: 10.3171/2011.3.JNS 101574 
Wilent, W. B., Oh, M. Y., Buetefisch, C. M., Bailes, J. E., Cantella, D., Angle, C., et al. (2010). Induction of panic attack by stimulation of the ventromedial hypothalamus. J. Neurosurg. 112, 1295-1298. doi: 10.3171/2009.9. JNS09577

Williams, R. H., Jensen, L. T., Verkhratsky, A., Fugger, L., and Burdakov, D. (2007). Control of hypothalamic orexin neurons by acid and $\mathrm{CO}_{2}$. Proc. Natl. Acad. Sci. U.S.A. 104, 10685-10690. doi: 10.1073/pnas.070267 6104

Woods, S. W., Charney, D. S., Goodman, W. K., and Heninger, G. R. (1988). Carbon dioxide-induced anxiety. Behavioral, physiologic, and biochemical effects of carbon dioxide in patients with panic disorders and healthy subjects. Arch. Gen. Psychiatry 45, 43-52. doi: 10.1001/archpsyc.1988.0180025 0051007

Yeoh, J. W., Campbell, E. J., James, M. H., Graham, B. A., and Dayas, C. V. (2014). Orexin antagonists for neuropsychiatric disease: progress and potential pitfalls. Front. Neurosci. 8:36. doi: 10.3389/fnins.2014. 00036
Conflict of Interest Statement: The authors have reviewed the journal's policy and have the following competing interests: PB, CD, BS, SY, CP, BL, DN, NC, and TL are paid employees at Janssen Research \& Development, LLC. This does not alter the authors' adherence to the journal's policies on sharing data and materials.

The other authors declare that the research was conducted in the absence of any commercial or financial relationships that could be construed as a potential conflict of interest.

Copyright (c) 2017 Bonaventure, Dugovic, Shireman, Preville, Yun, Lord, Nepomuceno, Wennerholm, Lovenberg, Carruthers, Fitz, Shekhar and Johnson. This is an open-access article distributed under the terms of the Creative Commons Attribution License (CC BY). The use, distribution or reproduction in other forums is permitted, provided the original author(s) or licensor are credited and that the original publication in this journal is cited, in accordance with accepted academic practice. No use, distribution or reproduction is permitted which does not comply with these terms. 